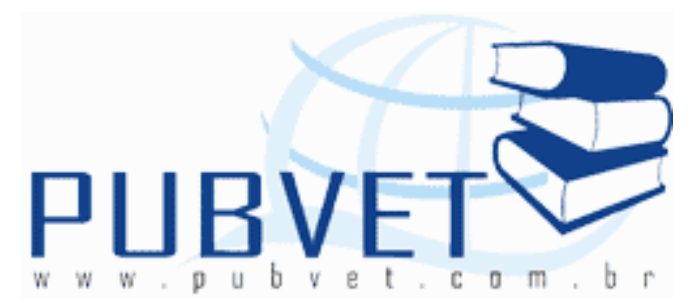

PUBVET, Publicações em Medicina Veterinária e Zootecnia.

\title{
Produção de leite, dinâmica do peso, condição corporal, infecção parasitária e análise econômica de ovelhas da raça Bergamácia mantidas em pasto e confinamento
}

\footnotetext{
Edicarlos Oliveira Queiroz¹; Edson Ramos de Siqueira²; Andressa Santanna Natel $^{3}$; Cláudia da Costa Boucinhas ${ }^{4}$; Luiz Carlos Vieira Júnior ${ }^{5}$ Heraldo César Gonçalves $^{6}$; Simone Fernandes ${ }^{7}$
}

${ }^{1}$ Zootecnista, Doutorando do curso de Pós - graduação em zootecnia, UEM, Maringá PR, ${ }^{*}$ Autor correspondência: queirozed@yahoo.com.br

${ }^{2}$ Professor Titular do Departamento de Produção Animal, FMVZ-UNESP, Botucatu-SP.Pesquisador CNPq

${ }^{3}$ Zootecnista, Mestre em zootecnia, FMVZ-UNESP, Botucatu-SP

${ }^{4}$ Zootecnista autônoma e Doutora pela FMVZ-UNESP, Botucatu - SP

${ }^{5}$ Zootecnista, Doutorando em Zootecnia, FMVZ-UNESP, Botucatu, SP, Brasil

${ }^{6}$ Professor Titular do Departamento de Produção Animal, FMVZ-UNESP, Botucatu-SP. Pesquisador CNPq

${ }^{7}$ Zootecnista-Aux.Acadêmica Produção Animal, FMVZ - UNESP, Botucatu - SP

\section{Resumo}

Avaliou-se o efeito do sistema de alimentação sobre a produção de leite, dinâmica do peso e condição corporal, infecção parasitária e análise econômica entre os sistemas. Foram utilizadas 31 ovelhas da raça Bergamácia, sendo que 14 delas foram mantidas em pasto de Panicum maximum cv. Tanzânia e as 
outras 17 foram mantidas em confinamento, alimentadas com silagem de milho e concentrado na proporção $85: 15 \%$ no terço final da gestação e 65:35\%, durante a lactação. Os cordeiros foram separados das mães 48 horas pós-parto. As ovelhas foram ordenhadas mecanicamente duas vezes ao dia, às 4 e 14 horas. A produção de leite foi mensurada diariamente, por sessenta dias. Não houve diferença entre os sistemas de alimentação quanto à produção de leite; as ovelhas do confinamento apresentaram-se mais pesadas $(P<0,05)$ que as mantidas em pasto por todo o período da lactação. O número de ovos por grama de fezes das ovelhas mantidas em pasto foi maior $(P<0,05)$ que das ovelhas confinadas durante o periparto, ao parto, durante a lactação e ao fim da lactação.

Palavras-chave: lactação, ovino, sistema de produção

\title{
Milk production, dynamic weight, body condition, parasite infection
} and economic analysis of Bergamasca ewes maintained on pasture and feedlot

\begin{abstract}
The objective of this work was to evaluate the effect of feeding on milk production, body weight and corporal condition dynamics, parasitic infection and economic analysis between production systems. Two groups of Bergamácia sheep were used. 14 animals were grazed and 17 were penned during the final end of pregnancy, and 60 days period of lactation, fed with corn silage and concentrate diet at $85: 15 \%$ ratio at the third end of gestation an $65: 35 \%$ ratio. Lambs were separated from mothers 48 hours after parturition. Sheep were mechanical milked and milk production was measured twice a day, at 4:00 and 14:00 hours. There was no difference between treatments for milk production and feedlot ewes presented higher live weight than that kept at pasture during the whole lactation. It was not observed difference for body condition at lambing. Ewes kept at pasture presented
\end{abstract}


QUEIROZ, E.O. et al. Produção de leite, dinâmica do peso, condição corporal, infecção parasitária e análise econômica de ovelhas da raça Bergamácia mantidas em pasto e confinamento. PUBVET, Londrina, V. 6, N. 14, Ed. 201, Art. 1350, 2012.

higher values of eggs per gram of faeces than feedlot ewes from pre-lambing to end lantation.

Keywords: lactation, sheep, production systems

\section{Introdução}

Ovinos da raça Bergamácia de origem italiana, com aptidão leiteira podem ser encontrados no Brasil, entretanto sendo utilizados para a produção de carne. Entretanto, poderiam ser utilizados para a produção leiteira, contudo, a quantidade de leite produzido e a persistência da lactação ainda são pouco conhecidas.

Aproximadamente $25 \%$ do leite produzido durante uma lactação são produzidos nos primeiros 30 dias pós-parto (FOLMAN et al., 1966). Entretanto, alguns fatores podem alterar o nível de produção durante uma lactação, como o ambiente, a raça, idade da ovelha, estádio da lactação, número de cordeiros, técnicas de ordenha, estado sanitário, manejo do rebanho e nível nutricional durante a gestação e lactação (PEETERS et al., 1992; BENCINI \& PULINA, 1997).

A utilização de sistemas mais intensivos devido em parte, aos baixos índices de produtividade do rebanho ovino, tem aumentado nos últimos anos. Vinculado a esta mudança, é eminente o interesse em pesquisar a produção de leite de pequenos ruminantes (FUENTE et al., 1997).

A diminuição dos índices de endoparasitoses pode ser conseguida por meio da implantação do confinamento, além de melhorar a eficiência e a produtividade do rebanho (MOREIRA, 1997). Ao estabelecer este sistema, as dietas devem ser compatíveis com as exigências da categoria animal, associadas à finalidade e ao potencial de produção (SIQUEIRA, 1993).

Objetivou-se avaliar o efeito do sistema de alimentação (pastagem e confinamento) sobre a produção de leite, dinâmica do peso e da condição corporal, infecção parasitária e análise econômica entre os sistemas. 
QUEIROZ, E.O. et al. Produção de leite, dinâmica do peso, condição corporal, infecção parasitária e análise econômica de ovelhas da raça Bergamácia mantidas em pasto e confinamento. PUBVET, Londrina, V. 6, N. 14, Ed. 201, Art. 1350, 2012.

\section{Material e métodos}

O experimento foi realizado na Unidade de Pesquisa em Produção de Leite de Ovelha da Faculdade de Medicina Veterinária e Zootecnia da Universidade Estadual Paulista (UNESP), Campus de Botucatu - São Paulo, durante os meses de Setembro a Dezembro de 2007.

No último mês de gestação 31 ovelhas nulíparas da raça Bergamácia com idade média de 2 anos foram distribuídas, de acordo com o peso e condição corporal similares, em dois tratamentos, que consistiam em dois sistemas de produção, sendo: pasto (P) e confinamento (C).

No sistema a pasto, 14 ovelhas foram mantidas em capim Tanzânia (Panicum maximum cv. Tanzânia) manejado em sistema de lotação rotacionada, durante toda lactação. As demais 17 ovelhas, foram confinadas até o final da lactação, alimentadas com silagem de milho e concentrado (Tabela 1), na proporção 85:15 (11,3\% PB e 65\% NDT) para terço final da gestação e 65:35 no período de lactação (13,4\% PB e 65\% de NDT) segundo as exigências do NRC (1985).

Amostras da pastagem foram coletadas a cada 14 dias e encaminhadas ao laboratório de bromatologia da FMVZ-UNESP/Botucatu para análise de matéria seca (MS), proteína bruta (PB), fibra em detergente ácido (FDA), fibra em detergente neutro (FDN) e extrato etéreo (EE), segundo Silva (1990).

Durante o terço final da gestação até as três primeiras semanas de lactação que coincidiram com o início da primavera, devido à ocorrência de estiagem prolongada, as pastagens não disponibilizaram matéria seca suficiente aos animais; em vista disto foram suplementadas com silagem de milho. As ovelhas que estavam em pasto receberam $1,70 \mathrm{~kg}$ de matéria seca (MS) de silagem durante o terço final de gestação e $1,3 \mathrm{~kg}$ de MS durante as três primeiras semanas de lactação. Ambos os tratamentos receberam sal mineral à vontade (Techsal) fornecido em cocho separado durante todo o período experimental. 
Tabela 1. Ingredientes utilizados na formulação do concentrado

\begin{tabular}{ccc}
\hline Ingredientes & $\%$ na MS & Valor $(\mathrm{R} \$)$ \\
\hline Milho moído & 15,00 & 0,52 \\
Farelo de soja & 32,48 & 0,76 \\
Farelo de trigo & 48,52 & 0,66 \\
Calcáreo & 4,00 & 0,24 \\
Total & $100 \%$ & 0,73 \\
\hline
\end{tabular}

Todas as ovelhas foram ordenhadas mecanicamente (Westfalia Tipo RO) com 4 conjuntos de ordenha e linha de leite baixa (120 pulsos/min e nível de vácuo de $36 \mathrm{Kpa}$ ), em sala de ordenha com plataforma e capacidade para dez ovelhas. Antes de iniciar a ordenha as tetas dos animais foram desinfetadas com solução de iodo glicerinado e após ação do mesmo, foram secos com papel toalha. Realizaram-se duas ordenhas, às 4 e 14 horas com produção de leite mensurada a cada ordenha.

Para ambos os tratamentos adotaram-se o sistema de desmama precoce em que os cordeiros foram separados de suas mães 48 horas pós-parto e aleitados com leite de vaca até 45 dias de idade.

Os pesos das ovelhas foram tomados ao parto, e a cada 14 dias até os 60 dias de lactação em balança digital, juntamente com a condição corporal (CAÑHEQUE et al. 1989), atribuídas notas de 1 a 5, fracionada em 0,25, sendo 1 para animais extremamente magros e 5 para os obesos.

As infestações endoparasitárias foram monitoradas a cada 14 dias, por meio da coleta de amostras de fezes, diretamente na ampola retal, em todas as ovelhas. Os animais com resultados de ovos por grama de fezes (OPG) acima de 500 foram desverminados. O exame de fezes foi realizado pela técnica de GORDON E WHITLOCK (1939).

Para análise econômica foram calculados os custos de produção e receita, para os dois sistemas de produção, separadamente.

Para o cálculo da pastagem, utilizou-se o valor de $\mathrm{R} \$ 0,08$ centavos por $\mathrm{kg}$ de matéria seca; $\mathrm{R} \$ 3,75$ reais à hora trabalhada. 
As análises estatísticas foram analisadas no Sistema para Análises Estatísticas e Genéticas - Saeg (UFV, 2000). Os dados experimentais foram analisados como parcelas subdivididas no delineamento inteiramente casualizado. As médias foram comparadas pelo teste de Tukey, com probabilidade de $(P<0,05)$. Para os dados não paramétricos (Escore Corporal), utilizou-se o Teste Wilcoxon.

\section{Resultados e discussão}

As análises bromatológicas do pasto (Panicum maximum cv. Tanzânia), da silagem de milho (Zea mays) e do concentrado constam na tabela 2.

Tabela 2. Análises bromatológicas do pasto, silagem e concentrado

\begin{tabular}{|c|c|c|c|c|}
\hline \multirow[t]{2}{*}{ Nutrientes } & \multicolumn{2}{|c|}{ Pasto } & \multirow[t]{2}{*}{ Silagem } & \multirow[t]{2}{*}{ Concentrado } \\
\hline & Novembro & Dezembro & & \\
\hline MS (\%) & 22,2 & 25,6 & 38,90 & 87,33 \\
\hline PB (\%) & 8,6 & 7,9 & 7,39 & 27,08 \\
\hline NDT (\%) & 51,6 & 50,0 & 70,65 & 75,21 \\
\hline FDN (\%) & 66,2 & 67,0 & 61,82 & 26,20 \\
\hline FDA (\%) & 35,1 & 35,5 & 33,18 & 12,73 \\
\hline
\end{tabular}

MS: Matéria seca; PB: Proteína bruta; NDT: Nutrientes digestíveis totais; FDN: Fibra em detergente neutro; FDA: Fibra em detergente ácido

Não houve diferença entre os tratamentos quanto à produção de leite (Tabela 3). No início da lactação a quantidade de volumoso (silagem) oferecida às ovelhas que estavam em pasto foi similar às que foram mantidas em confinamento, o que ocorreu por três semanas pós-parto, já que o pasto não era suficiente para atender as necessidades nutricionais para a fase requerida. Sobretudo os teores protéicos e energéticos da silagem mostraram-se menor que o encontrado na pastagem, o que ocorreu a partir da $3^{a}$ semana de lactação. 
QUEIROZ, E.O. et al. Produção de leite, dinâmica do peso, condição corporal, infecção parasitária e análise econômica de ovelhas da raça Bergamácia mantidas em pasto e confinamento. PUBVET, Londrina, V. 6, N. 14, Ed. 201, Art. 1350, 2012.

As diferenças entre as semanas de lactação na produção de leite só foram observadas a partir da $6^{a}$ semana, quando as ovelhas encontravam-se no final da lactação. A alimentação fornecida pode ter sido suficiente para atender as exigências de manutenção e produção das ovelhas mantidas em pasto e no confinamento, o que manteve a similaridade entre os tratamentos.

Braghieri et al. (2006) compararam a produção de leite de ovelhas da raça Merino em pastagem e confinamento, e verificaram que os animais mantidos em pastagem produziram $1048 \mathrm{ml} / \mathrm{dia}$ e as ovelhas confinadas $853,04 \mathrm{ml} / \mathrm{dia}$.

Com ovelhas multíparas da raça Bergamácia suplementadas ou não com gordura protegida e ordenhadas uma vez ao dia, Emediato (2006), verificou a mesma produção de leite para grupo controle e suplementado com gordura protegida respectivamente.

Tabela 3. Médias de produção de leite $(\mathrm{g})$ das ovelhas da pastagem $(\mathrm{P})$ e do confinamento (C) nas oito semanas de lactação

\section{Semanas}

\begin{tabular}{c|cccccccc|c}
\hline $\begin{array}{c}\text { Trata- } \\
\text { Mento }\end{array}$ & $\mathbf{1}^{\mathbf{a}}$ & $\mathbf{2}^{\mathbf{a}}$ & $\mathbf{3}^{\mathbf{a}}$ & $\mathbf{4}^{\mathbf{a}}$ & $\mathbf{5}^{\mathbf{a}}$ & $\mathbf{6}^{\mathbf{a}}$ & $\mathbf{7}^{\mathbf{a}}$ & $\mathbf{8}^{\mathbf{a}}$ & Média \\
\hline $\mathbf{P}$ & 760 & 691 & 738 & 777 & 714 & 668 & 596 & 565 & 688 \\
$\mathbf{C}$ & 937 & 861 & 898 & 895 & 883 & 799 & 684 & 621 & 822 \\
\hline $\begin{array}{c}\text { Média } \\
\text { Semana }\end{array}$ & $848^{\mathrm{a}}$ & $776^{\mathrm{ab}}$ & $818^{\mathrm{ab}}$ & $836^{\mathrm{a}}$ & $799^{\mathrm{ab}}$ & $733^{\mathrm{bc}}$ & $640^{\mathrm{cd}}$ & $593^{\mathrm{cd}}$ & \\
\hline
\end{tabular}

Médias seguidas de letras iguais, nas linhas, não diferem entre si pelo teste de Tukey $(P<0,05)$;

O pico de lactação da ovelha segundo Zeppenfeld et al. (2002) encontrase bem definido na quarta semana de lactação; Sá (2001), com a raça Bergamácia, observou maior produção na segunda e quarta semanas. No presente trabalho não ficou claro o período em que ocorreu o pico de lactação, provavelmente pelo sistema de desmama adotado que proporcionou uma produção constante de leite e queda moderada de acordo com as semanas de 
QUEIROZ, E.O. et al. Produção de leite, dinâmica do peso, condição corporal, infeç̧ão parasitária e análise econômica de ovelhas da raça Bergamácia mantidas em pasto e confinamento. PUBVET, Londrina, V. 6, N. 14, Ed. 201, Art. 1350, 2012.

lactação, ao passo que as maiores produções podem ser observadas na primeira semana de lactação quando ocorreu a desmama, após 48 horas pósparto (Figura 1).

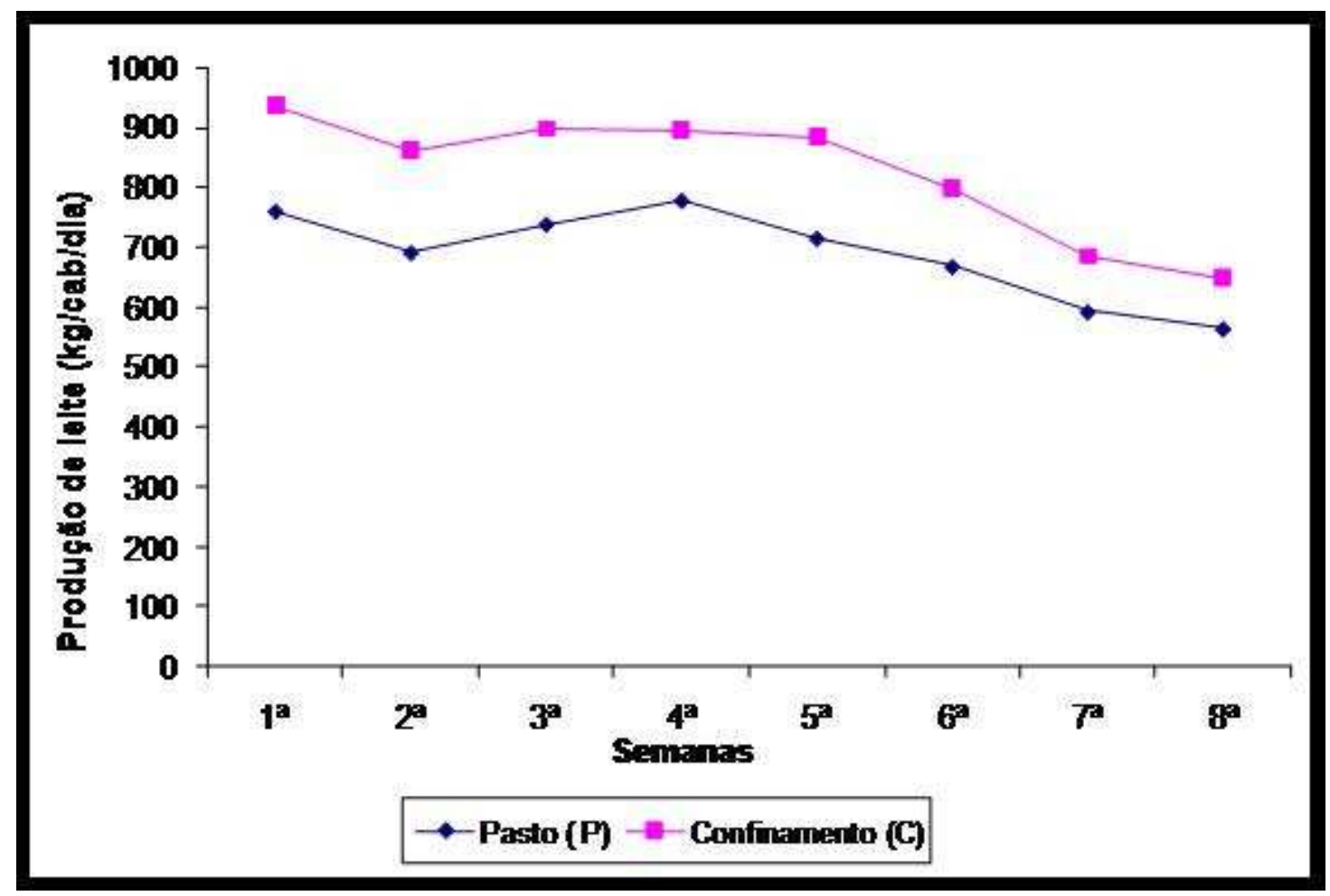

Figura 1. Produção média semanal de leite das ovelhas da raça Bergamácia

A renovação do pasto favoreceu o aumento da produção de leite das ovelhas da pastagem atendendo as exigências de manutenção e produção das ovelhas, como pode ser observado na figura 1 , onde a produção das ovelhas em pasto acompanhou a curva de produção das ovelhas mantidas em confinamento.

Gutiérrez (1991), Peeters et al. (1992) e Cérdotes et al. (2003) afirmaram que oscilações no plano nutricional ao longo da lactação podem influenciar de forma decisiva na produção leiteira. 
QUEIROZ, E.O. et al. Produção de leite, dinâmica do peso, condição corporal, infecção parasitária e análise econômica de ovelhas da raça Bergamácia mantidas em pasto e confinamento. PUBVET, Londrina, V. 6, N. 14, Ed. 201, Art. 1350, 2012.

Tabela 4. Peso $(\mathrm{kg})$ e condição corporal (notas de 1 a 5 , onde 1 : extremamente magra e 5: extremamente gorda) das ovelhas, ao parto, aos 15, 30, 45 e 60 dias de lactação

\begin{tabular}{|c|c|c|c|c|c|}
\hline \multirow{2}{*}{ Momentos } & \multicolumn{2}{|c|}{ Peso (Kg) } & \multicolumn{3}{|c|}{ Condição Corporal } \\
\hline & $\mathbf{P}$ & $\mathbf{C}$ & CV (\%) & $\mathbf{P}$ & $\mathbf{C}$ \\
\hline Ao Parto & $52,89^{A b}$ & $57,47^{\mathrm{BCa}}$ & 10,10 & $2,48^{\mathrm{Aa}}$ & $2,51^{\mathrm{Ca}}$ \\
\hline 15d lact & $53,00^{A b}$ & $55,41^{\mathrm{Da}}$ & 12,08 & $2,50^{A b}$ & $2,75^{\mathrm{Ba}}$ \\
\hline 30d lact & $53,89^{A b}$ & $56,97^{C D a}$ & 11,68 & $2,46^{\mathrm{ABb}}$ & $2,80^{\mathrm{Ba}}$ \\
\hline 45d lact & $54,67^{A b}$ & $58,82^{A B a}$ & 12,14 & $2,33^{A B b}$ & $2,95^{\mathrm{Aba}}$ \\
\hline 60d lact & $54,28^{A b}$ & $60,17^{\mathrm{Aa}}$ & 11,82 & $2,23^{\mathrm{Bb}}$ & $3,13^{\mathrm{Aa}}$ \\
\hline
\end{tabular}

Médias seguidas de letras diferentes minúsculas nas linhas e maiúsculas nas colunas diferem entre si $(P<0,05)$ pelo teste de Wilcoxon

Observa-se na tabela 4 que as ovelhas do confinamento apresentaram-se mais pesadas em todo o período da lactação, quando comparadas com as ovelhas da pastagem. Houve uma queda nos pesos médios para as ovelhas do confinamento aos 15 dias de lactação devido a duas ovelhas que manifestaram mastite clínica com perda de peso, o que não ocorreu aos animais mantidos em pasto. Cavani et al. (1991) não observaram perda de peso durante os 64 dias de lactação, concordando com estes resultados, que demonstrou ganhos em ambos os tratamentos.

Aos 60 dias de lactação as ovelhas confinadas tiveram pesos mais elevados que as ovelhas mantidas em pasto, período em que a diferença ficou mais evidente.

Godfrey et al. (1997) observaram variação de peso durante toda lactação de ovelhas mantidas em confinamento, ocorrendo maiores perdas aos 21 e 28 dias pós-parto, e somente a partir desta fase iniciaram a recuperação do peso perdido nas primeiras semanas. Boucinhas et al. (2006) verificaram diferenças ao parto para ovelhas mantidas em pasto com suplementação $(56,47 \mathrm{~kg})$ e 
QUEIROZ, E.O. et al. Produção de leite, dinâmica do peso, condição corporal, infecção parasitária e análise econômica de ovelhas da raça Bergamácia mantidas em pasto e confinamento. PUBVET, Londrina, V. 6, N. 14, Ed. 201, Art. 1350, 2012.

sem $(54,44 \mathrm{~kg})$ como também aos 70 dias de lactação $(53,41$ e 50,64 kg respectivamente).

Verifica-se na tabela 4 que não houve diferença para a condição corporal ao parto entre as ovelhas dos tratamentos, ao contrário dos períodos subseqüentes. As ovelhas da pastagem tiveram sensível perda na condição corporal após a segunda semana de lactação até o final do período da mesma, enquanto as ovelhas confinadas recuperaram esse escore.

Boucinhas et al. (2006) não encontraram diferenças para condição corporal ao parto para ovelhas suplementadas ou não suplementadas; mas obtiveram melhores valores para ovelhas aos 70 dias de lactação em pasto com suplementação $(1,87)$ do que somente em pasto $(1,57)$.

Ao final da lactação a diferença entre as condições corporais das ovelhas submetidas aos dois sistemas de produção foi bastante significativa, 2,23 para ovelhas da pastagem e 3,13 para as confinadas. Brito et al. (2006) observaram a dinâmica da condição corporal das ovelhas Lacaune quando vazias, durante a gestação e início e final da lactação, com médias de 3,14; 3,$00 ; 2,87$ e 3,28 , respectivamente.

De maneira geral as ovelhas mantiveram-se em boas condições em ambos os tratamentos, todavia as ovelhas confinadas finalizaram a lactação em condições adequadas para reproduzirem-se.

Em ovelhas lactantes, assim como em vacas, o consumo de alimento aumenta gradativamente com a demanda de energia no decorrer da lactação; no entanto, a demanda energética aumenta mais rapidamente do que o consumo de matéria seca no início da lactação. Por isso, as reservas corporais da ovelha são importantes para a produção de leite e o acúmulo se dará no final da lactação, quando o consumo supera a demanda energética (SPEEDY, 1980). 
QUEIROZ, E.O. et al. Produção de leite, dinâmica do peso, condição corporal, infeç̧ão parasitária e análise econômica de ovelhas da raça Bergamácia mantidas em pasto e confinamento. PUBVET, Londrina, V. 6, N. 14, Ed. 201, Art. 1350, 2012.

Tabela 5. Médias de ovos por grama de fezes (OPG) de ovelhas mantidas em pasto e confinamento

\begin{tabular}{ccc}
\hline OPG & \multicolumn{2}{c}{ Tratamentos } \\
& Pasto & Confinamento \\
\hline Periparto & $7.735,71^{\mathrm{a}}$ & $3.758,82^{\mathrm{b}}$ \\
Parto & $2.221,42^{\mathrm{a}}$ & $970,58^{\mathrm{b}}$ \\
Lactação & $714,28^{\mathrm{a}}$ & $152,94^{\mathrm{b}}$ \\
Fim da lactação & $478,57^{\mathrm{a}}$ & $0,0^{\mathrm{b}}$
\end{tabular}

Médias seguidas de letras diferentes na linha diferem entre si $(P<0,05)$

Houve diferença $(P<0,05)$ para o número de ovos por grama de fezes durante o periparto, ao parto, lactação e fim de lactação, entre os sistemas de produção como apresentado na tabela 5 . No periparto as ovelhas da pastagem apresentaram maiores valores de OPG que as confinadas, entretanto observase uma queda brusca das contagens de OPG após o parto, em ambos os tratamentos.

A partir da segunda semana de lactação não foi necessária a utilização de anti-helmínticos para as ovelhas confinadas que chegaram ao fim da lactação com OPG zero. As ovelhas da pastagem sempre apresentaram altas contagens de OPG (acima de 500), e precisaram ser desverminadas, com a utilização de várias dosificações, o que pode elevar o custo de produção e colaborar para resistência anti-helmíntica.

Amarante et al. (1992) constataram um aumento da contagem de ovos por grama de fezes, próximo ao parto, mantendo-se elevado até o fim da lactação. Já O'sullivan \& Donald (1970) observaram maiores contagens de OPG no início do que no final da lactação; e um acentuado aumento na eliminação de ovos de nematódeos foi observado em ovelhas das raças Red Maasai e Dorper no período do periparto (WANYANGU et al. 1997).

Utilizando 3,5\% de gordura protegida na suplementação de ovelhas da raça Bergamácia, Stradiotto (2007), encontrou diferenças na contagem de ovos por grama de fezes apenas aos 15 dias de lactação, com OPG de 2600 para ovelhas suplementadas e de1300 para o grupo não suplementado. 

parasitária e análise econômica de ovelhas da raça Bergamácia mantidas em pasto e confinamento. PUBVET, Londrina, V. 6, N. 14, Ed. 201, Art. 1350, 2012.

Nota-se que para as ovelhas de ambos os tratamentos houve queda de OPG após o parto; contudo nos animais da pastagem o OPG sempre mantevese alto, com necessidade de tratamento anti-helmíntico, como apresentado na figura 2.

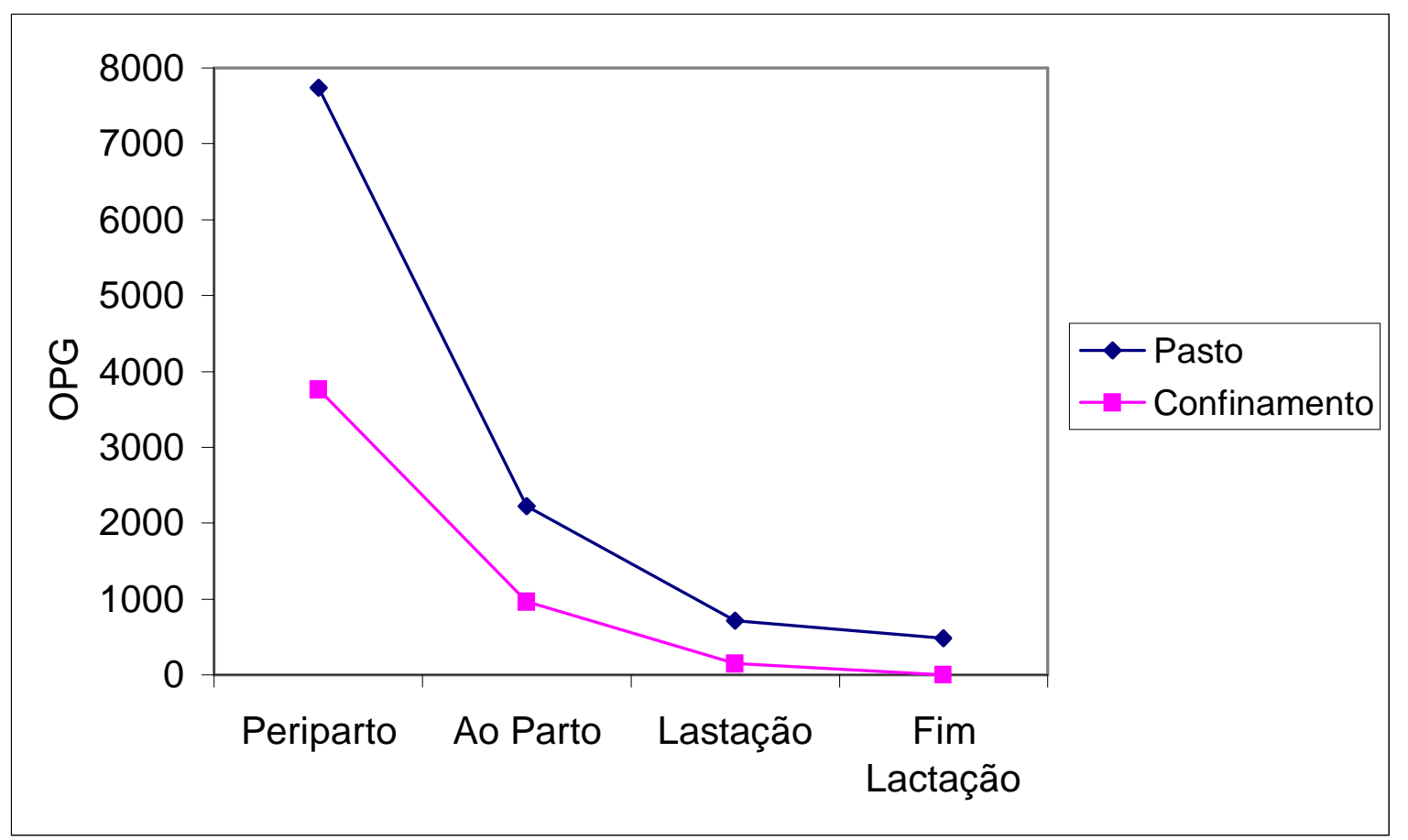

Figura 2. Valores de contagem de ovos por grama de fezes (OPG) de ovelhas da raça bergamácia em pastagem e em confinamento

Ambos os tratamentos mostraram-se viáveis para implantação, contudo o sistema de produção em pasto mostrou-se mais lucrativo. O custo da alimentação foi de $53,35 \%$ do custo total para as ovelhas confinadas e $31,87 \%$ em pasto de acordo com os resultados da tabela 6 . O lucro obtido foi de $R \$$ 665,05 para o sistema em pastagem e $\mathrm{R} \$ 131,16$ para o sistema onde os animais permaneceram confinados; considerando-se $\mathrm{R} \$ 3,20$ o valor do litro do leite de ovelha. 
QUEIROZ, E.O. et al. Produção de leite, dinâmica do peso, condição corporal, infecção parasitária e análise econômica de ovelhas da raça Bergamácia mantidas em pasto e confinamento. PUBVET, Londrina, V. 6, N. 14, Ed. 201, Art. 1350, 2012.

Tabela 6. Análise econômica da produção de leite de ovelhas da raça Bergamácia em pasto e confinamento

\begin{tabular}{|c|c|c|c|c|}
\hline & $\begin{array}{l}\text { Pasto } \\
\mathrm{n}=14\end{array}$ & $\begin{array}{l}\text { Unidade } \\
\text { ov/dia }\end{array}$ & $\begin{array}{l}\text { Confinamento } \\
\mathrm{n}=17\end{array}$ & $\begin{array}{l}\text { Unidade } \\
\text { ov/dia }\end{array}$ \\
\hline $\begin{array}{l}\text { Produção de } \\
\text { leite }(\mathrm{kg}) 60 \\
\text { dias }\end{array}$ & 578,75 & 688,92 & 839,32 & 822,87 \\
\hline $\begin{array}{l}\text { Receita (R\$ } \\
3,20 / \mathrm{kg} / \text { leite) }\end{array}$ & 1852,00 & 132,28 & 2685,82 & 157,99 \\
\hline \multicolumn{5}{|l|}{ Despesas } \\
\hline $\begin{array}{l}\text { Volumoso: } \\
\text { (silagem } \\
\text { milho) }\end{array}$ & 254,25 & 18,16 & 616,95 & 36,29 \\
\hline $\begin{array}{l}\text { Pasto } \\
\text { Concentrado: }\end{array}$ & 210,00 & 15,00 & 662,94 & 38,99 \\
\hline Minerais & 126,00 & 9,00 & 153,00 & 9,00 \\
\hline Mão-de-obra & 225,00 & 16,07 & 675,00 & 39,70 \\
\hline $\begin{array}{l}\text { Vermífugo } \\
\text { Mat. Limpeza }\end{array}$ & 29,60 & 2,11 & 20,00 & 1,18 \\
\hline $\begin{array}{l}\text { da sala } \\
\text { ordenha }\end{array}$ & 252,00 & 18,00 & 306,00 & 18,00 \\
\hline $\begin{array}{l}\text { Saquinhos p/ } \\
\text { envazar leite } \\
\text { Pré e Pós }\end{array}$ & 28,90 & 2,06 & 42,15 & 2,48 \\
\hline diping & 47,20 & 3,37 & 57,12 & 3,37 \\
\hline $\begin{array}{l}\text { Medicamentos } \\
\text { (mastite) }\end{array}$ & 14,00 & 1,00 & 21,50 & 1,26 \\
\hline $\begin{array}{l}\text { TOTAL } \\
\text { DESPESAS } \\
(\mathrm{R} \$) \\
\end{array}$ & 1186,95 & 84,79 & 2554,66 & 150,27 \\
\hline $\begin{array}{l}\text { LUCRO TOTAL } \\
(\mathrm{R} \$)\end{array}$ & 665,05 & 47,50 & 131,16 & 7,72 \\
\hline
\end{tabular}

Além do maior custo da alimentação, o sistema de confinamento exige mais mão-de-obra, fatos que explicam a maior lucratividade dos animais em pasto. Estes resultados poderiam ser diferente com maior número de ovelhas ou com animais de maior produção de leite, o que reforça a tese de que o produtor pode utilizar-se de ambas as técnicas, permitindo a utilização das 
QUEIROZ, E.O. et al. Produção de leite, dinâmica do peso, condição corporal, infecção parasitária e análise econômica de ovelhas da raça Bergamácia mantidas em pasto e confinamento. PUBVET, Londrina, V. 6, N. 14, Ed. 201, Art. 1350, 2012.

pastagens quando forem abundantes e o confinamento durante o período de estiagem.

Macedo (1998) obteve melhor retorno econômico quando analisou a produção de carne de cordeiros em pastagem e confinamento; quando os cordeiros confinados apresentaram retorno de $(+R \$ 269,13)$. Emediato (2006) fez uma simulação de resposta de capital, levando em consideração o custo de alimentação das ovelhas, e obteve retorno de $R \$ 81,54$ e $R \$ 84,24$ por ovelha para os grupos sem suplementação e com suplementação de gordura protegida, respectivamente.

\section{Conclusões}

As produções de leite para ovelhas confinadas ou mantidas em pasto não diferiram por todo o período de lactação.

O sistema de produção de leite em confinamento apresentou menor lucro, devido principalmente às despesas com alimentação e mão-de-obra; entretanto as ovelhas finalizaram o período de lactação em condições adequadas para reproduzirem-se.

As ovelhas do confinamento demonstraram menor infecção parasitária.

\section{Referências bibliográficas}

AMARANTE, A.F. T; et al. Eliminação de ovos de nematóides gastrintestinais por ovelhas de quatro raças durante diferentes fases reprodutivas. Pesquisa Agropecuária Brasileira, $v$. 27, p. 47-51, 1992.

BENCINI, R.; PULINA, G. The quality of sheep milk: a Review. Australian Journal of Experimental Agriculture, v.45, n.3, p. 182-220, 1997.

BOUCINHAS, C.C; SIQUEIRA, E.R; MAESTÁ, S. A. Dinâmica do peso e da composição corporal e eficiência reprodutiva de ovelhas da raça Santa Inês e mestiças Santa Inês x Suffolk submetidas a dois sistemas de alimentação em intervalos entre partos de oito meses. Ciência Rural, v.36, p. 904-909, 2006.

BRAGHIERI, A.; PACELLI, C.; VERDONE, A.; GIROLAMI, F.; NAPOLITANO. Effect of grazing and homeopathy on milk production and immunity of Merino derived ewes. Small Ruminant Research, v 13. p.1-8, 2006.

BRITO, M.A; GONZÁLEZ, F.D et al. Composição do sangue e do leite em ovinos leiteiros do sul do Brasil: variações na gestação e na lactação. Ciência Rual, v.36, n.3, p.942-948, 2006.

CAÑHEQUE, V. ET AL. Producción de carne de cordero. Madrid: Colección Técnica Ministerio de Agricultura, Pesca y Alimentación, 1989. 550p. 
CAVANI, C; BIANCONI, L; MANFREDINI, M; RIZZI, L; ZARRI, M. Effects of a complete diet on the qualitative characteristics of ewe milk and cheese. Small Ruminant Research. V. 5, p.273-284, 1991.

CÉRDOTES, L. et al. Produção e composição do leite de vacas de corte de quatro grupos genéticos submetidas a dois manejos alimentares no período de lactação. In: REUNIÃO ANUAL DA SOCIEDADE BRASILEIRA DE ZOOTECNIA, 40., 2003, Santa Maria, RS. Anais... Santa Maria: Sociedade Brasileira de Zootecnia, 2003. 5p. Cd-Rom.

EMEDIATO, R.M.S. Efeito da gordura protegida sobre parâmetros produtivos de ovelhas da raça bergamácia e na elaboração de queijos. Dissertação apresentada ao curso de Pós Graduação em Produção e Nutrição animal, FMVZ - UNESP, Botucatu- SP. 2006. $106 \mathrm{p}$.

FOLMAN, Y.R; VOLCANI ; EYEL.E. Mother-offspring relationship in Awassi sheep. I: The effect of different suckling regimes and time of weaning on the lactation curve and milk yield in daity flocks. J.Agric.Sci. v.67, p. 359-368, 1966.

FUENTE, L.F; SAN PRIMITIVO, F; FUERTES, J.A; GONZALO, C. Daily and between-milking variations and repeatabilities in milk yield, somatic cell count, fat, and protein of dairy ewes. Small Ruminant Research. v. 24, p. 133-139, 1997.

GODFREY, R.W; GRAY, M.L; COLLINS, J.R. Lamb growth and milk production of hair and woll sheep in a semi-arid tropical environment. Small Ruminant Research. v. 24, p.77-83, 1997.

GORDON, H.M; WHITLOCK, H.V. A new technique for counting nematode eggs in sheep faeces. Journal Counc. Science Ind. Research, v.12, p.50-52, 1939.

GUTIÉRREZ, R.B. Elaboración artesanal de quesos de ovejas. Montevideo-Uruguay: MGAP - JUNAGRA - UAPAG, 1991. 130p

MACEDO, F. A.F. Desempenho e características de carcaça de cordeiros corriedale e mestiços bergamácia $x$ corriedale e hampshire down $x$ corriedale, terminados em pastagem e confinamento. Botucatu, SP: Faculdade de Medicina Veterinária e Zootecnia UNESP, 1998, 72p. Tese (Doutorado em Zootecnia) - Faculdade de Medicina Veterinária e Zootecnia - UNESP, 1998.

MOREIRA, N. Quem disse que é inviável confinar? A Granja. N. 580, p 59-61, 1997.

National Research Concil. Nutrients requirements of sheep. Washington: National Academy Press Inc., 1985.

O'SULLIVAN, B.M.; DONALD, A.D. A field study of nematode parasite population in the lacting ewe. Parasitology, v.61, p. 301-315, 1970.

PEETERS, R.; BUYS, N.; ROBIJNS, L.; VANMONTFORT, D.; ISTERDAEL, J.V. Milk yield and milk composition of Flemish milk sheep, Suffolk and texel ewes and their crossbreds. Small Ruminant Research, v.7, p.279-288, 1992.

SÁ, C.O. Influência do fotoperíodo na produção de leite e níveis de hormonais de ovelhas da raça Bergamácia. Botucatu, SP: UNESP, 2001.87p. Tese (Doutorado em Zootecnia)-Universidade estadual Paulista, 2001.

SAEG. (UNIVERSIDADE FEDERAL DE VIÇOSA) UFV. Sistema de Análises Estatísticas e Genéticas. Versão 7.0 Viçosa-MG, 2000.150p. (Manual do usuário).

SILVA, D.J. Análise de Alimentos (Métodos Químicos e Biológicos), Viçosa, Imprensa Universitária, 160p. 1990.

SIQUEIRA, E. R.; AMARANTE, A. F. T.; FERNANDES, S. Estudo comparativo da recria de cordeiros em confinamento e pastagem. Vet. Zoot., v.5, p.17-28, 1993.

SPEEDY,A.W. Manual de criação de ovinos. Lisboa: Proença, 219p, 1980. 
STRADIOTTO, M.M. Efeito da gordura protegida sobre a composição centesimal do leite, anestro pós-parto, resposta às infecções parasitárias e desempenho dos cordeiros, em ovelhas da raça Bergamácia. Botucatu, SP: UNESP, 2007. 89p. Dissertação (Mestrado em Zootecnia)-Universidade Estadual Paulista, 2007.

WANYANGU, S.W. et al. Response to artificial and subsequent natural infection with haemonchus contortus in Red Maasai and dorper ewes. Veterinary Parasitology, v.69, p. 275-282, 1997.

ZEPPENFELD, C.C.; PIRES, C.C.; CARDOSO, A.R. ET al. Produção de Leite e consumo de ovelhas e borregas com primeira cria aos doze meses e ganho de peso dos filhos. In: REUNIÃO ANUAL DA SOCIEDADE BRASILEIRA DE ZOOTECNIA, 39. 2002 Recife. Anais... Recife: SBZ, 2002. 